\title{
De la identidad
}

desdichada al suicidio

francés: el pensamiento

neoreaccionario

de Alain Finkielkraut

y Eric Zemmour* /

From a Simple an

Unhappy Identity to

The French Suicide:

Alain Finkielkraut

Neo-reactionary

thinking and Eric

Zemmour

* Artículo de investigación. Recibido: 29 de noviembre de 2017. Aceptado: 17 de abril de 2018. Tla-Melaua, revista de Ciencias Sociales. Facultad de Derecho y Ciencias Sociales. Benemérita Universidad Autónoma de Puebla, México / E-Issn: 2594-07 16 / Nueva Época, año 12, núm. 45, octubre 2018-marzo 2019, pp. 52-72. 
RESUMEN

El presente estudio describe algunas obras de los polemistas franceses Alain Finkielkraut y Eric Zemmour, protagonistas del pensamiento neoreaccionario en Francia. Estos intelectuales son críticos de la multiculturalidad. Sus reflexiones insisten en la preservación de la cultura occidental y en el rechazo a las civilizaciones que no asimilan los valores del pensamiento ilustrado. Su posicionamiento deslegitima, también, el fenómeno de la posmodernidad; proponen una reintegración de las estructuras tradicionales que han permitido los valores comunitarios e individuales de Europa. A últimas fechas, han radicalizado sus invectivas contra los musulmanes e inmigrantes en el país galo dadas las consecuencias del terrorismo. En conjunto, la ideología de estos personajes permite entender el núcleo de la derecha francesa y europea donde el estilo neoreaccionario se vuelve fundamental. Para una interpretación adecuada del texto, es importante señalar que no todo antineoliberal es conservador y que la confusión destaca la necesidad de reflexionar al respecto.

\section{PALABRAS CLAVE}

Derecha alternativa, neorreaccionario, conservadurismo, Francia, islam.
A B STRACT

The present study describes some works of the French polemicists Alain Finkielkraut and Eric Zemmour, two of main representatives of the neoreactionary thought in France. These intellectuals are critical of multiculturalism. They are pro supporters of the preservation of Western culture and the reject anything that does not assimilate the values of enlightened thought. Their position delegitimizes, postmodernity; they consider traditional structures as the reason for communal and individual values in Europe. In recent years, they have radicalized their invectives towards Muslims and immigrants in France due to terrorist attacks. Finkielkraut's and Zemmour's ideologies provide a perspective on how The French and European Right adopted the neo-reactionary way of thinking as fundamental. In order to arrive to the adequate interpretation of this writing it is important to establish that not all anti neoliberals are conservatives and this misinterpretation highlights the need to reflect on this way of thinking.

KEYWORDS

Alternative right, neo-reactionary, conservatism, France, Islam.

\footnotetext{
* Profesor investigador en la Facultad de Derecho y Ciencias Sociales de la Benemérita Universidad Autónoma de Puebla, México. (golda21@hotmail.com) orcid.org/0000-0002-6845-3706
} 
1. Introducción / 2. Alain Finkielkraut y la Francia desdichada / 3. Eric Zemmour: suicidio y masculinidad / 4. La nación y Charles De Gaulle / 5. La inmigración / 6. Cabildeo y minorías influyentes / 7. La juventud poderosa / 8. Conclusión: discursos de odio y activismo político / 9. Bibliografía

\section{INTRODUCCIÓN ${ }^{1}$}

El presente texto se propone responder a dos preguntas: ¿En qué medida los intelectuales neorreaccionarios en Francia influyen en la opinión pública? ¿Por qué esta corriente de pensamiento que defiende tesis radicales es una de las más perceptibles en el país galo? Para ello, se describe y analiza el trabajo de los pensadores Alain Finkielkraut y Eric Zemmour.

Zemmour viene de la comunidad judía de Argelia; Finkielkraut, de una familia polaca que huyó de los campos de Auschwitz. Uno es profesor, filósofo y escritor; el otro, un crítico de programas de televisión que hablan de la sociedad gala. Alain Finkielkraut y Eric Zemmour, ambos calificados como "neorreaccionarios", representan a algunos de los intelectuales franceses más conocidos del periodo contemporáneo. Manifiestan la indignación y la crítica hacia el fundamentalismo islámico, la incapacidad gubernamental y la nueva derecha que se presenta como la alternativa política efectiva.

Eric Zemmour nació el 31 de agosto de 1958 en una familia de origen modesto. Después de estudiar en el Institut Politique de Paris, fracasa dos veces para entrar a l'Ecole Normale d'Administration. Sin embargo, en 2006 formó parte del jurado. Ahora se califica a sí mismo como el "digno heredero del periodismo francés".

A partir de 1986, Zemmour empezó a hacer periodismo en el Quotidien de Paris; este fue el principio de una larga carrera. Trabaja en Le Figaro, Marianne o Valeurs Actuelles. Su periodismo no tiene siempre la misma línea política. Votó por el izquierdista Francois Mitterrand en 1981 y 1988, y por el candidato de la derecha en 2007 Nicolas Sarkozy. A partir de 2003, participó en la emisión de televisión "Ca se dispute"; y después, en "On est pas couché", donde tuvo que criticar libros, películas y recopilaciones.

Desde el 4 de enero de 2010 anima una emisión en la cadena de radio $R T L$ “Z come Zemmour" donde critica la actualidad. Su facultad para atacar tanto a políticos de izquierda como de derecha es la misma. Sin embargo, Jean Marie Lepen, el líder de la extrema derecha francesa, consideraba a

\footnotetext{
${ }^{1}$ Agradezco a Gaël Yerbe Henrick, Amélie Agnés Nolar y Cecile Marie De Cassin Victoria, por su valiosa colaboración durante el proceso de escritura de este trabajo.
} 
Zemmour como "unos de los únicos que actúan correctamente con ella". Para Eric Zemmour, la política hace parte de su trabajo y de sus pasiones. Escribió algunos retratos políticos sobre Edouard Balladur (Balladur, immobile à grands pas, 1995) o Jacques Chirac (L'Homme qui ne s'aimait pas, 2002). Ganó el premio de la "libertad de expresión" en 2010. Después de su experiencia en la radio, publicó un libro para que "caigan las máscaras": Le bûcher des vaniteux, en 2011. Quiere que todo tipo de sensibilidad política sea comprometida. A propósito de la inmigración, su punto de vista es radical: "quiere que se acabe".

Es un ferviente partidario de la "asimilación". En este movimiento, todo particularismo cultural o religioso debe desaparecer y los emigrantes tienen que abandonar sus culturas de origen. Sin embargo, sus opiniones sobre la inmigración le suponen algunos problemas con la justicia. Respecto a las mujeres, en su libro Le premier sexe (2006), dice de las feministas que son unas "demagogas".

Alain Finkielkraut nació en 1949, en una familia que huyó a Polonia durante la Segunda Guerra Mundial. Este filósofo, intelectual, escritor y profesor en la escuela Polytechnique tiene otros "maestros". Admira sin límites a los filósofos como Hannah Arendt o Hans Jonas. Fue nominado a la Academia Francesa en 2014 y entró oficialmente en enero de 2016. Publicó muchos libros de reflexión, como Le fuif imaginaire (1981), La sagesse de l'amour (1984), La Défaite de la pensée (1987) y varios artículos. A partir del 21 de septiembre de 1985, anima una emisión semanal de radio en France Culture que se llama Répliques.

Este conservador escéptico se caracteriza por su postura provocativa y tradicional. Como lo dice él mismo: "soy el portavoz de nadie". Critica algunos aspectos de la modernidad y califica a internet de "basurero". Se interesa mucho sobre algunos temas como la escuela de la república con su papel de profesor. Reflexiona sobre el antisemitismo, acerca de la identidad de los judíos de su generación en su libro Le fuif imaginaire (1981). Se presenta como un defensor de las pequeñas naciones. Tiene una concepción muy firme sobre la inmigración. Según Finkielkraut, el problema es que numerosos inmigrantes tienen odio por la cultura francesa y no hacen esfuerzos. En el periódico israelí Haaretz se enfada con los "negros" y los árabes. Otra polémica famosa ocurre cuando atacó al equipo nacional de futbol que califica de "black-black-black".

Estos dos intelectuales tienen una trayectoria distinta, pero, aparentemente, pertenecen a la misma familia de críticos no convencionales. Son atacados por la prensa y, sin embargo, siguen muy activos en todo tipo de medios de comunicación. Zemmour y Finkielkraut se aferran a una ideología "buen pensante", sin temor de impactar a su público. Ambos se oponen al concepto de antirracismo de los años ochenta. Para ellos, es lo típico del "buen pensamiento" y debemos contar con eso. Este buen pensamiento va a contracorriente; por eso, adoptan posturas muy incómodas en la opinión pública. 
Están marcados en su ideología por los eventos que afectaron profundamente a la sociedad francesa, en mayo de 1968: la revuelta estudiantil que puso en duda las estructuras políticas, sociales y tradicionales. Durante este periodo, Finkielkraut estuvo preparando su concurso para l'Ecole Normale Superieur. Regresó a París, como maoísta e izquierdista. Hoy en día, entiende al movimiento de manera crítica por su ideología progresista. Considera que, de haber triunfado los universitarios, habrían provocado un tipo de guerra civil. En nombre de la igualdad, se opone al antirracismo. A su vez, Zemmour denuncia la destrucción de lo que llama las "estructuras tradicionales", como familia, patria, nación e Iglesia.

Ahora, la sociedad francesa vive una destrucción que continúa la iniciada en 1789. Antes estaba el enfrentamiento entre las estructuras tradicionales y el individuo que quería emanciparse. A partir de 1968, las estructuras tradicionales están muertas. El individuo es rey; se queda solo y pierde el control. No hay estructuras tradicionales para controlarlo.

Ambos eruditos han entrado en conflicto con la justicia por sus ideas. Finkielkraut tiene juicios por difamación en abril 1999, en 2007 y 2008. También Zemmour, en 2011, fue condenado por sus palabras en dos cadenas de televisión, donde decía que "la mayoría de los traficantes son negros o árabes", o bien, que Francia debería bombardear Molenbeek - el barrio musulmán en Bruselas - a raíz de los ataques terroristas en París durante 2016. El 22 de septiembre de 2015, fue denunciado por un caso de incitación al odio racial y a la difamación sobre los musulmanes que expresó en el periódico italiano Corriere della Sera.

En los siguientes párrafos, la pretensión es describir algunas de las ideas y argumentos, a modo de guía, que más identifican a ambos personajes.

\section{Alain Finkielkraut y LA Francia DEsdichada}

Existe una clara voluntad del autor para persuadir y subrayar, desde sus primeras frases, que el pasado inmediato de Francia era mejor. Así, en Finkelkraut se percibe una forma de reacción tradicionalista que va a diferir del tipo de actitud reaccionaria de Zemmour, que es más violento y machista.

Empieza su desarrollo refiriéndose al movimiento estudiantil de 1968. Entonces Finkielkraut era estudiante y, como la mayoría, participó activamente en este "momento de gracia". El movimiento social promocionó la esperanza de "cambiar la vida"; pero, según él, eso fue solamente una utopía, como lo muestra el fracaso de mayo del 68. Así, la ilusión era esa voluntad de romper con las estructuras sociales en Francia. Sin embargo, Finkielkraut constató que esa generación formaba parte del mismo. Con todo, el movimiento permitió la creación de un nuevo tipo de individuo de su generación: el bobo (persona con un buen capital social que se caracteriza por preferencias culturales 
específicas, urbano, ecológico, idealista e izquierdista), al cual Finkiekraut describe como un "adulto-adolescente".

La primera parte de su libro se llama "La mixité française", que se puede traducir como "La mezcla francesa". Se pone claramente en favor de una república francesa unida a través de la laicidad. Finkielkraut va a dar su opinión sobre la laicidad a través del ejemplo del velo y de la burqa. Todo empieza por el concepto de "galantería", que explica la tradición del cortejo desencadenada por el encantamiento femenino. Para Finkielkraut, la cortesía se refiere a una atmosfera necesaria para los hombres. Por añadidura, señala que esa tradición sigue existiendo en Francia: "el antiguo régimen galante sigue sobreviviendo en la modernidad republicana".

Precisamente compara al velo, "símbolo de la tradición", con el pantalón que, al contrario, es un "símbolo de modernidad". Este proceso de ocultación de las mujeres a través del velo o de la burqa es la "solución elegida por la mayoría de las sociedades" para "evitar el terrible deshonor de ser engañado por su mujer". Así se explica, por un lado, que los hombres en la comunidad espiritual del islam tengan pánico a la infidelidad y, por otro, la violencia en los barrios marginales de inmigrantes, donde la exclusión de la feminidad produce un desierto afectivo. En estos barrios existe una verdadera prohibición para ejercer la galantería.

Denuncia el velo porque, desde su enfoque, indica que las mujeres constituyen "una afrenta potencial al orden público". Así, se declara a favor de la norma que prohíbe la disimulación de la cara. Señala que es "contrario a los principios de fraternidad y de civilidad" y simboliza un rechazo para entrar en contacto con el otro. Con la multiplicación de velo integral, o de la burqa, afirma que "ya no se siente en su país", y añade que rechaza ver "transformar las costumbres en opción facultativa". Es por eso que Francia eligió la opción de la prohibición. Sin embargo, según él, lo del velo no significa que Francia es injusta con la humanidad libre; al contrario, las mujeres ahora deben "existir como sujeto y no solamente en la mirada del hombre". Además, a ellos que dicen que prohibir el velo no es una vía republicana, Finkielkraut replica con una gradación cada vez más fuerte que no sólo constituye eso, sino también una vía para defender "principios de fraternidad, laicidad, igualdad"; y "un modo de estar-ser, una forma de vida, un tipo de sociabilidad [...] una identidad común".

La segunda parte de su libro, "Le vertige de la désidentification" ("El vértigo de la desidentificación"), trata de la inmigración europea con la noción de integración. Debate el concepto de igualdad. Primero, le parece que la noción de identidad nacional es la hija de la igualdad, "porque fue permitido por la generalización del sentimiento del parecido". Sin embargo, opone la igualdad del romanticismo político (corriente de ideas del fin del siglo XVIII que hace prevalecer el sentimiento sobre la razón y considera que 
el hombre es, ante todo, el resultado de la historia) con la igualdad de las luces (movimiento filosófico que dominó el mundo de las ideas en Europa durante el siglo XVIII).

Para la Ilustración, la igualdad se parece al hombre autónomo. Considera que el pensamiento ilustrado descuida el "tesoro de sabiduría" que es la costumbre. Así, el hombre nace con "una deuda que debe honrar". Por eso no se puede, como lo pretenden las luces, dejar atrás el pasado con los derechos naturales, porque, como lo señala Burke, los derechos son hereditarios de los antepasados y eso es lo que permite que el presente sea distinto. Finkielkraut concluye con la frase "El universalismo es una ilusión".

Posteriormente, intenta explicar la inmigración masiva en Francia y Europa. Así, esa "inmigración con fines de reforzar la población" es aceptada por los países europeos porque representa para ellos "una suerte de redención". Europa quiere olvidarse y hacerse perdonar las sombras de su pasado. Por eso, ahora, ha dejado de "convertir" al otro e intenta, más bien, "reconocer al otro". Ya no existe la asimilación que Finkielkraut conoció en su pasado. Su orgullo de ser al mismo tiempo judío y francés se ha tornado en una disposición demasiado compleja. Ahora, Francia reconoce al otro no como parte de la nación sino como un sujeto con múltiples identidades. De hecho, el Estado tiene miedo de suspender los particularismos a riesgo de parecer antidemocrático o fascista.

Sobre el multiculturalismo, el filósofo habla respecto a la escuela y su papel educativo. En Francia, esta institución de la republica significa el lugar de la "celebración de la alteridad"; por eso, la noción de "franceses autóctonos" (galos) ahora está en la picota (el exotismo es la condición); es por ello que "las palabras de asimilación e integración pierden toda pertinencia". Eso conduce a considerar la expresión francés de cepa como algo desvalorizado. Se pregunta sobre este punto: si la alteridad predomina, ¿por qué tratar de unificarse en una sola nación? Para el autor, proscribir el término raza no es suficiente, pues al sustituirlo por el término cultura se "cumple la misma función funesta", fijando a los seres humanos en una pertenencia y un origen.

Finkielkraut denuncia la noción del universalismo heredero de la Ilustración, rehabilitando las ideas de Edmund Burke respecto a la igualdad entre los hombres. Niega a personas de confesión islámica el derecho de reivindicarse como franceses formando parte de la nación. Como Zemmour, Finkielkraut intenta justificar la aceptación de la inmigración por parte de las autoridades francesas y europeas como una forma de hacerse perdonar por una colonización abusiva. Eso conduce, según Finkielkraut, a una promoción exagerada de la alteridad y una negación del término de identidad, porque Francia es, ante todo, un país que promueve su diversidad.

La tercera parte de su libro se refiere a una forma de desintegración de la cultura y la promoción de una forma de modernidad perversa. En la sociedad 
francesa, se observa un rechazo de los libros cada vez mayor que tiene incidencias tanto en el lenguaje como en la promoción de la diversidad antes del mérito. Primero, señala que hay cada vez menos lectores en Francia, sobre todo en los adolescentes. Paralelamente, Finkielkraut atribuye a los libros la virtud de "aislarnos de la algarabía ambiental". Inicia una comparación opositora entre el libro y la pantalla para mostrar lo positivo del libro que no permite la pantalla.

Así, de acuerdo con sus ideas, el libro "reserva el lugar inviolable del pasado" y "despliega un tiempo donde el presente no puede penetrar". El libro se entiende y es percibido como "una entidad distinta": "propone un mundo", a diferencia de la pantalla que no permite esta ruptura con el presente y con el mundo ambiente.

Por añadidura, subraya que "la generación internet es la gran perdedora", porque leer un libro en una pantalla no se puede comparar realmente a una verdadera lectura con las ventajas que permite una obra. Señala que "el libro perdió la batalla de la lectura" y la escuela, que normalmente es la institución que debe promover el gusto de leer un libro en los adolescentes, "dejó las armas". Después, denuncia el sistema educativo y ataca las consignas transmitidas a los profesores: deben "elegir una problemática cercana a los alumnos", "una situación no exótica". Eso, según este autor, no permite la necesaria e indispensable "apertura a la vida" y constituye, solamente, un "cierre del presente sobre sí mismo".

Para mostrar la importancia de la literatura, cita el ejemplo del industrial Jean Curtius, quien afirmó como único camino viable para la identidad de Francia el "papel capital" de la literatura en la conciencia que tiene el país de sí mismo y de su civilización. Conjuntamente, observa a los intelectuales que para "tratar de las cosas importantes" usan las ciencias sociales; de esa manera, pierden su "superyó literario" que "permitía mantener la unidad de la lengua". Ahora, la conversación francesa "se apoltrona". Esos intelectuales ya no establecen la lengua, sólo la "acompañan".

En su opinión, este "pueblo culto" ya no existe por culpa de la "escuela abierta", con sus reformas (por ejemplo, la de 2013, que establece "el fin del monopolio de la lengua nacional en las clases"). Con eso surgió una "nueva sociedad donde todo el mundo usa el verbo "más confortable", donde "los locutores sólo hablan para ser entendidos", donde (señala Finkielkraut), en una enumeración de casos semejantes, "la mierda invade todo". Esa frase subraya bien su denuncia, "Para el nuevo régimen semántico la forma no tiene ningún valor, sólo el sentido tiene sentido". El igualitarismo y el "culto por la diversidad" tienen su culpa.

Acusa, también, el hecho de que la sociedad eligió un modelo del hombre, donde el individuo "se realiza desinhibiéndose". Incluso los políticos, que la sociedad pone de relieve por su capacidad estadista y visionaria, sólo "discuten 
con sus iguales, nunca con los siglos". Así, Finkielkraut querella la supresión de los exámenes de cultura general en los concursos administrativos y en el concurso del Institut Politique de Paris. Además, critica algunas asociaciones que defienden el antirracismo que, según él, pone "el origen por encima de la originalidad". Desde su punto de vista, si la diversidad y el multiculturalismo son elevados por encima de la nación, Francia "sacrifica lo mejor de su ser".

Finkielkraut enfatiza sobre una tradición en peligro: la lengua francesa. Bajo un análisis nostálgico, afirma que hubo un tiempo donde el idioma francés era distinto; ahora ninguna persona usa ese tipo de lenguaje, lo que contribuye a la desaparición del habla francesa, a su degeneración. En efecto, la primera evidencia de esta degeneración es la pérdida del tradicional libro físico. Finkielkraut constata el desamor, cada vez más fuerte, entre la juventud y los libros.

Finkielkraut, rompiendo totalmente con su estilo propio, hace un análisis relevante sobre la lengua francesa y señala el vocabulario que le indigna, para hacer tomar conciencia al lector sobre la ausencia de la forma en el habla y la falta de sentido en el idioma contemporáneo. Ya no es un placer leer o escuchar francés. El autor se queja de que la forma no sea importante para la gente cuando habla. Eso conduce al abandono de vocabulario.

Asimismo, denuncia la sustitución que no cambia nada de una a otra tradición francesa. Dada la supresión de los exámenes de cultura general en los concursos administrativos y escolares ante la Academia Francesa, se genera una ruptura con la tradición y la manera de integrar a las personas en el sistema educativo francés. Como Zemmour, denuncia que este hecho puso el origen (país de origen, religión, categoría social de pertenencia) por encima de la originalidad. Según él, esos exámenes de cultura general permitían validar un habitus aristocrático que se asimila a la elite y su capital social.

La cuarta parte del libro "La guerre des respects" ("La guerra de los respetos") enfatiza la noción de acatamiento en la sociedad francesa y la forma políticamente correcta a que conduce. La descripción más relevante de la "crisis actual del vivir-juntos" se encuentra en El Leviatán de Thomas Hobbes, lo que "revela un verdadero choque de civilizaciones". Hobbes describe bien el ejemplo el Estado de naturaleza que "fragiliza la idea de progreso". La violencia característica de Francia en el siglo XXI no viene de "las desigualdades o de la sed de adquisición", sino del "deseo de ser respetado y de lo que implica este deseo". Por otra parte, de acuerdo con Finkielkrauft, en función de su origen o de sus creencias, los individuos no tienen la misma "definición de lo malo". Por ejemplo, al explicar las manifestaciones de 2005 en París, por "el desempleo, la exclusión", se concedió, de manera graciosa, un alivio a los conglomerados que destruyeron propiedad privada en el país.

Posteriormente, intenta definir lo políticamente correcto. Le califica de "conformismo ideológico de nuestra época", refiriéndose a Alexis de Tocqueville 
(político e historiador francés del siglo XIX), quien señalaba que "la democracia produce conformismo". Subraya que "el hombre democrático cree que todo el mundo puede pensar por sí mismo". La democracia se vuelve el derecho de todos a hablar; empero, eso implica también una permisividad irresponsable. Expone que la "otra alternativa a lo políticamente correcto es lo políticamente abyecto". Esto termina por justificar "el sentimiento antifrancés que se extiende en Francia" como "una reacción de legítima defensa a la exclusión" y se esfuerza en analizar la violencia como derivada de las "causas sociales". Si lo antifrancés no se puede clasificar, para no afectar este principio de diversidad, se califica a las personas de "psicópatas".

Más tarde, la obra trata de explicar el comportamiento de los jóvenes actualmente. En la sociedad griega, más que contrato social, había el aidos, ${ }^{2}$ que se puede traducir como "modestia", "reserva" o "pudor". La educación, por primera vez en la historia francesa, ya no puede contar sobre el aido; así que la promoción por parte de la escuela de la espontaneidad junto a la "abolición de la censura" se puede asimilar (de acuerdo con Finkielkraut) a una vía abierta para el triunfo del "impudor de todos": cinismo social.

Esa eliminación del aidos conduce a una "falta de jerarquización en el lenguaje y en las relaciones humanas". La respuesta del gobierno francés para paliar esa falta de aidos es implementar "clases de moral laica", para que los jóvenes entiendan que "hay cosas que no se hacen" y que se den cuenta de "una deuda respecto a sus ancestros". Aunque Finkielkraut califica esta iniciativa de laudable, confirma que está abocada al fracaso porque entra en contradicción con lo que hace la escuela que erige esos alumnos como "sujetos soberanos" y los padres ya no pueden ayudar en la escuela porque no transmiten "en la casa el punto de vista de la escuela" y actúan cada vez más como si hubieran sido "los delegados sindicales de sus hijos".

Así, Finkielkraut señala que el aidos no es una "disposición natural", así que no es posible su desarrollo hoy porque el objetivo ya no es que el niño "sea educado", como lo quería la tradición, sino que "sea radiante", como lo promueven los defensores de la modernidad. Intenta explicar el comportamiento de los jóvenes en la escuela o en la sociedad debido a una falta de aidos y culpa a los padres de promover a sus hijos como reyes que pueden controlar todo pero desconocen la herencia, la tradición y los valores del pasado.

Finkielkraut denuncia la pérdida del aidos, sobre todo por parte de los jóvenes de las clases bajas. Explica la violencia en los barrios populares, marginados o inmigrantes de las ciudades por una búsqueda de respeto.

\footnotetext{
${ }^{2}$ Es una palabra difícil de traducir. Procede del griego clásico, dónde era de uso común. Significa algo así como la reverencia y la vergüenza que impiden a los hombres cometer malas acciones. Es una de las emociones personificadas en la mitología griega que Homero y Hesíodo consideraban como los sentimientos más nobles, una entidad presente al lado de Zeus. Afirma que se echa de menos su presencia en la conciencia de muchos hoy día.
} 
La enorme diferencia cultural entre los franceses de cepa y los inmigrantes ocasiona severos peligros en la coexistencia de grupos racialmente distintos. El malestar y la violencia en los barrios con una alta concentración de emigrantes no se explican sólo con la pobreza y la discriminación. Hay que tomar en consideración, además, las especificidades culturales de los nuevos llegados y la renuncia del sistema educativo y de las elites culturales a proponer la integración. Porque ya no creen en Francia como civilización.

La última parte de su libro se puede considerar un resumen que constata las recomendaciones de Finkielkraut. Desde su perspectiva, "el cambio ya no es lo que hacemos, sino lo que nos llega" y lo que llega es "la crisis del vivir-juntos". En Francia somos responsables de lo que ocurre en la medida que "descalificamos el aidos". La democracia no puede aceptar esta crisis porque no sólo es un "movimiento político", sino un "movimiento, una dinámica, un proceso histórico de supresión de la fronteras y de nivelación de las diferencias". "El régimen se encarga de la desintegración nacional”; pero el régimen está "cansado", mientras que el proceso se mantiene sin conocer ningún límite. Finkielkraut pregunta: “Todo está decidido?" Contesta que no, "si se elige enfrentarlo"; pero urge, "el tiempo apremia".

\section{ERIC ZEMMOUR: SUICIDIO Y MASCULINIDAD}

La narrativa de sus obras constituye una férrea defensa de la identidad francófona, así como de la soberanía de Francia. Independientemente del acuerdo o la inconformidad con Eric Zemmour, queda claro que sus argumentos pretenden generar una islamofobia. Además de contener un discurso reaccionario, es importante destacar en sus ideas una fuerte defensa de la masculinidad como estructura vertebral de la sociedad. ${ }^{3}$ Desde su perspectiva, el debilitamiento y pérdida de la figura paterna genera la feminización de la sociedad. Trata de explicar que esta disminución paternal empezó en el último cuarto del siglo xx y se hizo cada vez más fuerte hasta generar que el padre ya no represente la figura central de la familia y que el hombre ideal sea una verdadera mujer.

El autor afirma que la muerte del padre de familia ocurrió el 4 de junio de 1970. La expiración masculina fue generada por la mayoría conservadora como consecuencia del miedo a los movimientos estudiantiles de 1968. El temor de la sociedad permitió que las mujeres se apoderarán del "fuego sagrado de la procreación”. Así, la revolución de mayo impuso su ideología dentro de la familia. Advierte que Francia transitó de una familia percibida como "institución matricial que permite fundar un pueblo, una sociedad, una nación", hacia una familia percibida como "lugar privilegiado del amor y de

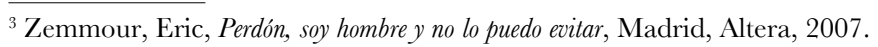


la felicidad privada". Por desgracia el "padre es la victima expiatoria de esa búsqueda de la felicidad".

Intenta justificar la importancia de la dominación del padre en una familia afirmando que es un error creer en la versión moderna familiar porque la figura del padre represivo y autoritario es la figura al nivel micro del Estado. Si el padre no tiene un rol de dominación, dicho fenómeno arriesga la influencia del Estado. Por ello, el padre necesita el apoyo de la sociedad. Finalmente, advierte, es la familia quien muere, y con esta desaparecerá la sociedad.

Sus argumentos también se dirigen contra la banalización del divorcio, cuyo símbolo son las canciones de Michel Delpech (Pour un flirt). El divorcio "banalizado y no culpabilizado" impulsa en Francia la época de los "divorcios en masas", que generan el fin del período donde "la perennidad de la familia era preferida a la felicidad de los individuos". Denuncia este "egoísmo individual de los adultos que nos piensan al equilibrio psicológico de los niños".

Sobre todo, critica a las mujeres. Después añade las "consecuencias económicas y sociales del divorcio": hay una pérdida de "30\% del poder adquisitivo". La más afectada es la mujer; el hombre es lastimado de otra manera: "su papel de padre es destruido, negado", porque, en todos los casos, bajo excepción, el niño siempre es "confiado a la madre". Así, la ley de 1975, previendo el divorcio por consentimiento mutuo, genera la emergencia de un nuevo tipo parental: "la familia recompuesta". Para Zemmour este esquema es "un oxímoron".

La visión del autor sobre el papel del padre en la familia es machista y mantiene un discurso violento respecto a la mujer. Denuncia la pérdida de virilidad, cada vez mayor, en tanto busca asimilar al hombre con la mujer. El hombre ideal se depila, compra productos de belleza, es feminista, prefiere el compromiso a la autoridad y la tolerancia antes que la lucha. El hombre ideal es una auténtica mujer. Acusa, entonces, ya que ellas no se pueden transformar en hombres, hay que convertir a los hombres en mujeres. Impulsar el lado femenino del hombre es algo inconcebible para Zemmour. Las ideas del intelectual generan la impresión de una persona que vive en una época donde los principios que regían la sociedad y la vida en pareja eran los del kiryarcado.

A través de la figura del divorcio, indica la decadencia de la estructura familiar. Retoma la influencia negativa de las canciones como cultura de masas (Daniel Balavoine, Mon fils ma bataille), capaces de pervertir la vida cotidiana. El autor manifiesta su aberración frente a las leyes que protegen las familias "modernas" y permiten las sociedades de convivencia o la unión de personas del mismo sexo. Zemmour está convencido de la anormalidad de una separación y del impacto negativo en el niño. No toma en cuenta las familias que pelean frente a sus hijos; empero, lo más característico es que su visión excluye toda posibilidad de tener una segunda o tercera oportunidad nupcial. 
Al paralelo de su denuncia sobre la desaparición de la figura del padre, se indigna ante el proceso de emancipación femenina que, de acuerdo con su punto de vista, se hace bajo mucho egoísmo por parte de las mujeres. El divorcio simbolizó un proceso de mayor independencia para la mujer, el cual se fortificó en 1975 con la legalización del aborto. Para nuestro personaje, las discusiones parlamentarias que conducen a la aprobación de esa ley simbolizan un "momento donde la razón cede a la emoción, el interés nacional al deseo de los individuos".

Paralelamente, refiriéndose a 1992, Zemmour intenta subrayar un cambio de concepción feminista respecto al hecho de dar a luz y a la relación con un hombre dentro de una pareja. En el pasado, las feministas renunciaban a tener hijos bajo argumentos racionales (habían entendido que sufrirían de una carencia: "la necesidad de protección y de sumisión" de un hombre); ahora, la nueva generación de feministas reivindica la maternidad además de la independencia, e imponen, bajo argumento del "igualitarismo diario", una partición equitativa de las tareas domésticas en pareja. Esto, según Zemmour, sólo es una maniobra egoísta, pues la mujer sólo busca su "realización profesional y personal".

Zemmour tiene una visión misógina que describe a las mujeres como egoístas y les reprocha buscar su felicidad, pues dicha búsqueda se hace en detrimento del hombre. El triunfo y la realización son elementos masculinos. Así, su explicación del divorcio podría conducirnos a creer que el hombre es una víctima de la legalización que beneficia a las mujeres y no tiene ninguna responsabilidad de los acontecimientos.

Finalmente, el intelectual señala que la evolución de las instituciones sociales domina los comportamientos sociales y sexuales. En su enfoque, las patologías en el país se desarrollan por la feminización de la sociedad. El feminismo es la castración del hombre.

\section{La nación y Charles de Gaulle}

Afirma Zemmour ${ }^{4}$ que es necesario el patriotismo para salvar a Francia. Subraya que la muerte de Charles De Gaulle, el 9 de noviembre de 1970, fue la última vez que París se convirtió en la capital del mundo. La gente venía a Paris, ante todo, por lo que representaba De Gaulle, quien era "el último gigante de la Segunda Guerra Mundial". Con ese deceso Francia, sin saberlo, "estaba muriendo también", "ya no existiría". Ha sido difícil sobrevivir sin el símbolo nacionalista francófono, "con la partida de De Gaulle enterramos a Francia".

\footnotetext{
${ }^{4}$ Zemmour, Eric, Mélancolie francaise, París, Fayard, 2010; Zemmour, Eric, Le Suicide français, París, Albin Michel, 2014.
} 
Los movimientos estudiantiles de la época generaron un cambio fundamental en la manera de actuar del general De Gaulle, fue afectado por "la ingratitud de sus hijos", el carácter categórico del héroe ya no fue el mismo. El caudillo fue engañado por la "bella estafa" de la izquierda. Para recuperar el afecto de la juventud, De Gaulle substituyó su "condición maurrasiana [compartida del teórico católico integrista Charles Maurras] y conservadora" por una visión "modernista, progresista, de un hombre en ruptura con su entorno y su clase social". Luego entonces, la visión contemporánea del general De Gaulle es una visión falsa.

Es inocultable la admiración de Zemmour por De Gaulle; de hecho, el libro expresa la pasión devota que despierta esta figura mítica y divina como padre de una nación. El símbolo resulta fuerte y la idealización demasiado extensa: si la nación francesa muere con De Gaulle, ¿cómo puede existir algún futuro positivo? El contexto es planteado como un elemento para exaltar el nacionalismo francés y encontrar a los enemigos de la patria.

\section{LA INMIGRAC IÓN}

Zemmour ${ }^{5}$ señala que la inmigración sólo sirve para deshacer, dividir y retrasar a Francia. La multiculturalidad es un símbolo de "pérdida de la nación"; se reemplazan familias tradicionales francesas por clanes inmigrantes que se reagrupan de modos diversos. La formación de barrios inmigrantes musulmanes constituye "la revancha de los partidores de la Argelia francesa sobre el general De Gaulle". El historiador de la derecha piensa que las políticas públicas para asimilar e integrar inmigrantes constituyen una "medida humanista que se revela una catástrofe administrativa, porque, después, aunque Francia ponga en vigor medidas solidarias, ellos no cambian".

Según Zemmour, los inmigrantes, así como los partidarios del reagrupamiento familiar, familias multiculturales y matrimonios multirraciales, hablan de "integración"; empero, generan todo lo contrario. En pocos años, "la inmigración cambiará la cara de Francia", pasará de una inmigración por motivo de trabajo a una inmigración que viene a apoderarse de todo el país. La "asimilación está haciéndose al revés", es decir, los franceses están adaptándose al extranjero. El gobierno está dejando nacer "un pueblo diferente dentro del pueblo francés"; un pueblo que se revela como "hostil a un querido y viejo país nostálgico". Ese pueblo inmigrante asiste "con sus sueños de revancha histórica poscolonial".

La afluencia extranjera en el país galo perjudica la educación, expresa el texto, y la evidencia se encuentra en los resultados que han tenido las "leyes Haby" sobre el colegio único desde 1975. El modelo constituido, a

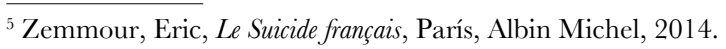


partir de entonces, ha provocado distintos descalabros. Primero, "sacrifica la cualidad de la enseñanza para la democratización"; lo que nunca hubiera hecho De Gaulle. Promueve un "desprecio de la memorización, del esfuerzo y del trabajo" para ser reemplazado por un "culto al niño y a su espontaneidad”. En segundo lugar, y más grave todavía, convoca a los hijos de inmigrantes el estudio con los niños franceses para evidenciar la "efectividad del reagrupamiento familiar", lo que genera "un público escolar con un mediocre nivel socio-cultural", así como una situación donde "la escuela y el conocimiento" no son promovidos dentro "de la escala de valores familiares occidentales".

De este modo, el gobierno obliga al país a servir de "remolque de los alumnos", lo que, paradójicamente, contribuye al crecimiento de las desigualdades sociales. Los hijos de inmigrantes deberían orientarse hacia la educación técnica; sin embargo, el pensamiento crítico de izquierdas los conduce a "menospreciar el idioma francés para la capacitación tecnológica", así como "rechazar ser los esclavos de los franceses como, según consideran, lo fueron sus antiguas generaciones". Desde esta perspectiva, "el liceo de Francia se volvió la escuela de nadie".

La obra mantiene sus ataques al multiculturalismo atendiendo las consecuencias del modelo de registro civil que ha favorecido la inmigración. Según Zemmour, en las poblaciones descendientes de la inmigración, la selección del nombre se asimila a "un signo político o en todo caso militante". Tomando la situación del nombre, considera que implica "el rechazo tácito de la asimilación que retrasa e impide la integración”. La selección del nombre genera el crecimiento de la brecha entre "nacionalidad de papel y nacionalidad de corazón", es decir, la separación clara entre "los franceses verdaderos" y los que nunca lo serán. Francia busca el perdón de su pasado imperialista y, por ello, trata de asimilar e integrar a diferentes poblaciones inmigrantes. Sin embargo, esta política pública es un error; esas personas jamás serán franceses, sino "excolonizados" que nunca perdonarán a la metrópoli.

El suicidio francés expresa la terrible ansiedad respecto de la inmigración que abarca una gran parte de la sociedad francesa judeocristiana. El inmigrante, como extranjero, llega a Francia con un revanchismo incontrolable. Su deseo es aprovechar las circunstancias para salvar su situación personal y la del país de origen. No pretende asimilarse ni busca la integración. El Estado ha cometido un grave error al procurar que estas personas contribuyan al engrandecimiento nacional. El multiculturalismo, la asimilación y la integración en diferentes temas de interés nacional representan profundas equivocaciones que costean los franceses verdaderos.

Zemmour busca proteger la cultura nacional gala. No obstante, pretende reinterpretar la identidad francesa, entendida como la tradición iluminada del siglo xIX, por el símbolo de la modernidad. La multiculturalidad ha demostrado 
sus errores en la asimilación de la población musulmana y ello conduce a fragmentar con múltiples clivajes la comunidad del país. Los inmigrantes no absorben los hábitos de convivencia franceses y, además, rechazan la identidad nacional al mantener los usos y costumbres de sus comunidades de origen. Son, un pueblo dentro de otro pueblo, pero no corresponden el apoyo y tolerancia de la sociedad receptora, por lo que la asimilación y la integración deben llegar a su fin. Lo mejor es que los inmigrantes se conserven como son; pero que vuelvan a sus países originales.

Las críticas a la integración y a la asimilación desentrañan los efectos de la inmigración en los franceses de cepa. Convivir con los inmigrantes y sus culturas ha sido negativo para el estilo de vida francés, la educación, el mercado y los hábitos cotidianos. Ni qué decir sobre el terrorismo. El autor preconiza que la islamización de Francia provocará que los grupos radicales y extremistas musulmanes tomen el control de todo. Considera que existe un complot árabe para dominar Europa. Francia debe disminuir la imagen de protección a los derechos humanos y poner orden en su interior, so pena de continuar admitiendo inmigrantes que buscan mejorar su vida económicamente y, al mismo tiempo, desarrollan una mentalidad de revanchismo hacia el país que los ha recibido.

El argumento sobre la educación cuestiona la mezcla inmigrante, valores y economía. La visión elitista y aristocrática del autor considera que la escuela debe reproducir los mejores valores de Francia y, por ello, no deben reunirse los niños franceses con los infantes inmigrantes. Los segundos deben ser encaminados a una educación técnica y diferenciadora socialmente. Los emigrantes no poseen el capital cultural, económico, social y político que pueda enaltecer a Francia. El modelo multicultural no ha podido evidenciar el modo en que el país podría aprovechar la inmigración; por el contrario, la experiencia ha sido costosa y trágica.

El autor presenta un retrato perverso del islam en Francia. El país vive una revolución negra que está minimizando los valores republicanos y cede ante las creencias fundamentalistas. El descontento con los musulmanes proviene de las revueltas juveniles de 2005 (banlieue), las manifestaciones en contra de la laicidad, las huelgas y los actos terroristas. Según Zemmour, la incompatibilidad entre Francia y el islam se observa en la juventud. Si bien es cierto que en los núcleos jóvenes existe desempleo, exclusión y desánimo por la crisis económica del país, ello es una generalidad. Sin embargo, la juventud con ascendencia musulmana empieza a involucrarse en el tráfico, robo, prostitución y las drogas. Hay núcleos radicales y fundamentalistas del islam que sustraen a los jóvenes de sus procesos de asimilación y los convencen fácilmente de volverse extremistas. Por eso, el autor intenta advertir la transformación de este "gueto ideológico y social" en un "gueto étnico-religioso". 
En las generaciones descendientes de inmigrantes, el acercamiento con el islam les cambia el sentimiento patriótico por la fidelidad a la umma, ${ }^{6}$ en la cual la pertenencia sectaria islámica prevalece sobre cualquier otra forma de ciudadanía. Los jóvenes musulmanes se involucran en la informalidad, una red de complicidades que les permite arropar cualquier clase de delitos y crímenes.

El intelectual de derecha piensa que, en las comunidades musulmanas europeas, se percibe la supremacía de un "nuevo poder islámico-mafioso" y confirma que "esos territorios" ya no son regidos por la ley republicana, sino que están organizados "en contra de la sociedad francesa y regidos por las prescripciones del islam".

Esta "conquista de territorio" por parte del islam es una forma de "contracolonizacion". El único objetivo del islam es extenderse y resistir contra la república y sus leyes. La clase política y oligárquica colabora con los grupos islamistas. Su multiculturalismo genera que el Estado de derecho republicano sea complaciente con los excesos musulmanes. Los tecnócratas actúan como aliados de los grupos islámicos y no hacen nada por detener al mundo musulmán que se refleja en Francia. El islam hace temblar al gobierno y a la sociedad.

La libertad, fraternidad e igualdad han sido sustituidas por la dictadura de lo políticamente correcto: el antirracismo y el comunitarismo islámico. El Estado francés se rinde ante las fatuas ${ }^{7}$ dictadas por los organismos subsidiados del pensamiento islamófilo contra los ciudadanos autóctonos.

La defensa que hace la población musulmana del burka, el velo y el burkini constituyen un grave "síntoma del inicio de una organización islámica alrededor" que cuestiona el principio jurídico de laicidad, así como la estrategia de la "asimilación". La discreción en la vida privada se ha convertido, durante la Francia asimilacionista, en un espacio donde el islam logra "imponer su modelo hostil, imperioso" a la sociedad francesa. Argumenta que con la ley de 2004 que prohíbe "los signos religiosos ostentosos", la republica "ganaba la batalla del velo en la escuela"; pero, sin darse cuenta, "perdía la guerra del halal", 8 porque la fuerza de la población musulmana consiste en imponer "su dominación cultural y cultual" a una sociedad que, ahora, rechaza objetarle cualquier cosa y acepta todas sus normas.

Para Zemmour, la multiplicación del halal en distintos campos sociales constituye un fracaso del asimilacionismo así como la irrefutable evidencia de que hay un "rechazo irreductible del islam de fundirse en el crisol francés", luego entonces, "para integrar el islam en Francia habría que renunciar a

\footnotetext{
${ }^{6}$ Comunidad de creyentes del islam.

${ }^{7}$ Pronunciamiento legal en el islam.

${ }^{8}$ Vocablo de origen árabe que significa "lícito", se utiliza en la comunidad islámica para referirse a todas aquellas acciones y comidas que son permitidas por la religión musulmana. Este término no sólo es utilizado para referirse a los alimentos, sino que también es aplicado para el día a día; por lo tanto, algo considerado halal puede resultar benéfico y saludable para el ser humano.
} 
mil años de historia". Argumenta bajo una óptica pesimista que "bajo el nombre de la república des-construimos Francia, bajo el nombre de los derechos humanos, erigimos un Estado dentro del Estado". Considera al islam como un "detonante de la desintegración del Estado-nación francés". La imposición del islamismo refuerza el "proceso de des-afrancesamiento y de islamización de los barrios franceses".

Si no se defiende a Francia, pronto la república de las luces será sustituida por el islam de las tinieblas. Francia morirá si no combate al islam. De acuerdo con el autor, es obligatorio impulsar acciones para bloquear el flujo migrante e incluso devolverlos a sus comunidades de origen. En lugar de generar políticas de asimilación e integración, hay que aplicar medidas de remigración; es decir, retornar a los migrantes a sus países. Francia puede tornarse en un país con mayoría afro-árabe musulmana que deba atender, sobre todo, la pobreza y los conflictos religiosos de estos grupos. Resulta imposible formar una nación donde cohabita una proporción creciente de población árabe-musulmana y africanos con comunidades francófonas. Ellos no quieren integrarse ni asimilarse. Cada vez más jóvenes de origen árabe, musulmán, africano o turco, incluso con nacionalidad francesa legal, se consideran como ciudadanos de su país mientras Francia es detestada.

Zemmour presenta una visión combativa frente al islam. Manifiesta que el mundo musulmán es incompatible con Francia y su historia. El islam es una religión que invade todos los sectores culturales en la sociedad. Su objetivo es implementar una contracolonización, lo cual parece conseguir, pues los controles ya no son rígidos en el país galo. No existe una ideología islámica moderada. En los inmigrantes musulmanes siempre habrá una inspiración revanchista, de combate y pugna contra los valores occidentales. Mientras Francia aprueba medidas a favor de la democracia, los derechos humanos, la tolerancia, la integración y la asimilación, los musulmanes no pierden tiempo en asesinar a la civilización occidental a sangre fría en el propio territorio francés. El riesgo de atentados terroristas en un país occidental es proporcional a la importancia numérica de su población musulmana. La situación obliga a prohibir la entrada de todo nuevo inmigrante musulmán y revertir los flujos migratorios.

\section{CABILDEO Y MINORÍAS INFLUYENTES}

Zemmour ${ }^{9}$ trata poner de relieve el poder y el peligro de estos lobbies. Considera que hay una influencia negativa por parte de ciertos grupos de presión que intervienen negativamente en las autoridades del país. Como primer caso, trata el lobby judío, uno de los más poderosos y respetados

\footnotetext{
${ }^{9}$ Zemmour, Eric, Le Suicide français, París, Albin Michel, 2014.
} 
por el régimen, independientemente del partido gobernante. Los apoyos, concesiones y financiamientos que obtienen los disponen por encima del interés nacional.

El lobby negro también es considerado como una organización que presiona a las autoridades al multiplicar los días conmemorativos de la esclavitud y las leyes memoriales para beneficiarse por encima del pueblo francés. Sin embargo, uno de los últimos grupos de presión que se han convertido en protagonistas de las políticas públicas, lo representa el lobby gay, que apareció en Francia durante 1985. Esta fecha se refiere a una boda organizada de manera ficticia (Thierry Le Luron et Coluche) que, conforme a Zemmour, constituye una verdadera ruptura en la manera de actuar del colectivo gay en la esfera pública.

En el pasado, estos personajes debían "abstenerse de toda publicidad"; pero, con los cambios ocurridos en los años setenta, "el sexo se volvió una identidad", y el homosexual, como los otros, "deseaba exhibir su amor". Manifiesta su oposición a las sociedades de convivencia y a la unión entre personas del mismo sexo: "una boda homosexual sólo puede ser una simulación paródica de la boda". Por desgracia, en su opinión, los gay "se imponen a una sociedad asombrada su modelo cultural y simbólico".

\section{LA JUVENTUD PODEROSA}

A lo largo de su obra, Zemmour acusa a la generación de 1968 de imponer los cambios progresistas que han lastimado al país galo; los califica de "rebelócratas". El espíritu de izquierdas que se desarrolló a partir de entonces ha debilitado al país y a la formación de juventudes desidiosas que no trabajan por su nación. El pensamiento progresista juvenil fomentó la drogadicción, el homosexualismo, el feminismo y la mayor parte de las patologías actuales. La generación marcada por los movimientos juveniles de los años sesenta y setenta en el siglo xx encumbraron a los inmigrantes y perdieron el orgullo nacional. El mal ejemplo que generaron fue la inconformidad, arrancar bienestar al país sin trabajar, romper el orden, devaluar la tradición y perder el nacionalismo. Esta conducta persiste en los jóvenes que sólo mediante la rebeldía y las revueltas establecen formas de comunicación.

\section{CONCLUSIÓN: DISCURSOS DE ODIO Y ACTIVISMO POLÍTICO}

¿Por qué estos discursos son los más audibles en la esfera intelectual y la clase media blanca francesa? Desde algunos años, se nota en el escenario público francés un acercamiento manifiesto de algunos intelectuales hacia las ideas de la derecha, incluso de extrema derecha. Algunos intelectuales en boga, como Eric Zemmour y Alain Finkielkraut, conocidos por sus polémicas posiciones 
en programas de debate, marcan el clima de opinión en Francia. Frente a este fenómeno, los periodistas y analistas, preocupados, se cuestionan y buscan las causas y explicaciones de las razones de este acercamiento hacia la extrema derecha, se cuestionan sobre la invisibilidad de los intelectuales de izquierda sobre el escenario audio-visual.

Se observan dos circunstancias interesantes. Primero, hay una dicotomía entre lo se espera de un intelectual y la manera de actuar de estos filósofos. Segundo, ¿son los intelectuales quienes se acercan a la política o son los políticos quienes utilizan a los intelectuales para dar más peso y legitimar sus ideas y reflexiones? Puede decirse que es un fenómeno de interacción mutua entre intelectuales y políticos.

¿Qué se espera de un intelectual? Lo primero es su capacidad de reflexión, o sea, su perspectiva para analizar una situación. Se supone que ayuda la sociedad a entender las situaciones complejas por la manipulación de conceptos abstractos. Gisèle Sapiro ${ }^{10}$ toma en consideración la distinción de Michel Foucault con respecto a los intelectuales. De un lado está el "intelectual específico" que cultiva su reflexión sobre un temario preciso; del otro lado, existe el "intelectual total", que se interesa en todos los asuntos y que, finalmente, en vez de desarrollar una reflexión basada sobre un juicio crítico da su opinión sobre todo sin tener un fundamento reflexivo. Por consiguiente, es una de las explicaciones de la visibilidad de estos intelectuales de derecha, como les etiquetan en el ámbito periodista.

A su vez, la actual era de redes y nuevos medios de comunicación da más importancia a la redundancia. Los intelectuales que se expresan sobre todos los asuntos toman ventaja sobre los demás intelectuales que se especializan sobre un tema. Así que la era mediática favorece la opinión libre en lugar del análisis y el exceso de opinión personal en lugar del juicio considerado.

Ahora bien, vale la pena enfocarse en el acercamiento entre este tipo de intelectuales neorreaccionarios y los políticos. Este vínculo se entiende en función de los intereses comunes: aumentar la audiencia pública. En otras palabras, se ayudan a socializar sus ideas y puntos de vista atrayendo la atención pública gracias a una sobreexposición mediática. Esta asociación entre el mundo intelectual y el mundo político muestra que las fronteras ideológicas son cada vez más borrosas. Por eso, se vuelve difícil entender la relación entre ambos. Más allá de una mezcla de dos elementos heterogéneos (políticos e intelectuales) se nubla la comprensión de la vida política dividida entre izquierda y derecha; se hace compleja la matriz de lectura de la política

\footnotetext{
${ }^{10}$ Sapiro, Gisèle, "L’inquiétante dérive des intellectuels médiatiques", Le Monde, 29 de abril. [Consulta: 15 de noviembre, 2017]. Disponible en: http://www.lemonde.fr/idees/article/2016/01/16/la-revolte-desclercs-contre-les-demunis_4848388_3232.html\#zEaHpGXUpu9TkgXL.99
} 
francesa. En otras palabras, la situación actual de las relaciones entre los mundos político e intelectual se explica por un círculo vicioso.

La confusión política reconocida por los analistas entre derecha e izquierda favorece una toma de posición radical de los intelectuales sobre hechos políticos, lo cual lleva a que se desdibuje la frontera entre el mundo intelectual y el mundo político. Por eso, esta mezcla refuerza la dificultad de entender la vida política. Los intelectuales totales se sirven de esta situación vaga para implantar sus ideas en el debate público. De hecho, se dice de manera popular que ya no se puede distinguir las ideas de la derecha política y las de la izquierda política; son muy similares por el contexto neoliberal y el discurso de progreso social.

Esta situación nublada favorece a las ideas de la extrema derecha. Entonces, ¿cómo interpretar el discurso de un intelectual que no entra a la matriz política tradicional? La lógica pretende que se le atribuya a la extrema derecha, ya que es el actor más claro de la vida política. Por consiguiente, se entiende un acercamiento de los intelectuales que toman posición política con el partido más inteligible de la vida política. Finalmente, es un efecto de convergencia entre estos dos mundos.

A modo de conclusión, cabe reafirmar que se necesita redefinir el problema. La cuestión no es el acercamiento de unos intelectuales a las ideas de la extrema derecha, sino al hecho de mayor visibilidad en los medios de comunicación. Hay una instrumentalización mutua entre los dos mundos: los intelectuales mediáticos se sirven de la situación borrosa de la vida política francesa para afirmar sus ideas que convergen con el partido de la extrema derecha, cada vez más visible sobre el escenario político. Los políticos alimentan esta visibilidad, provocando a estos intelectuales que es lo único que esperan.

\section{B I BLIOGRAF Í A}

Finkielkraut, Alain, La Identidad Desdichada, España, Alianza Editorial, 2014.

Sapiro, Gisèle, "L'inquiétante dérive des intellectuels médiatiques", Le Monde, 29 de abril. [Consulta: 15 de noviembre, 2017]. Disponible en: http://www. lemonde.fr/idees/article/2016/01/16/la-revolte-des-clercs-contre-lesdemunis_4848388_3232.html\#zEaHpGXUpu9TkgXL.99

Zemmour, Eric, Perdón, soy hombre y no lo puedo evitar, Madrid, Altera, 2007. Mélancolie francaise, París, Fayard, 2010. , Le Suicide français, París, Albin Michel, 2014. 